\title{
ДЕФОРМАЦИИ ПЕРЕДНЕГО ОТДЕЛА СТОПЫ ПРИ РЕВМАТОИДНОМ АРТРИТЕ: МИНИ-ОБЗОР
}

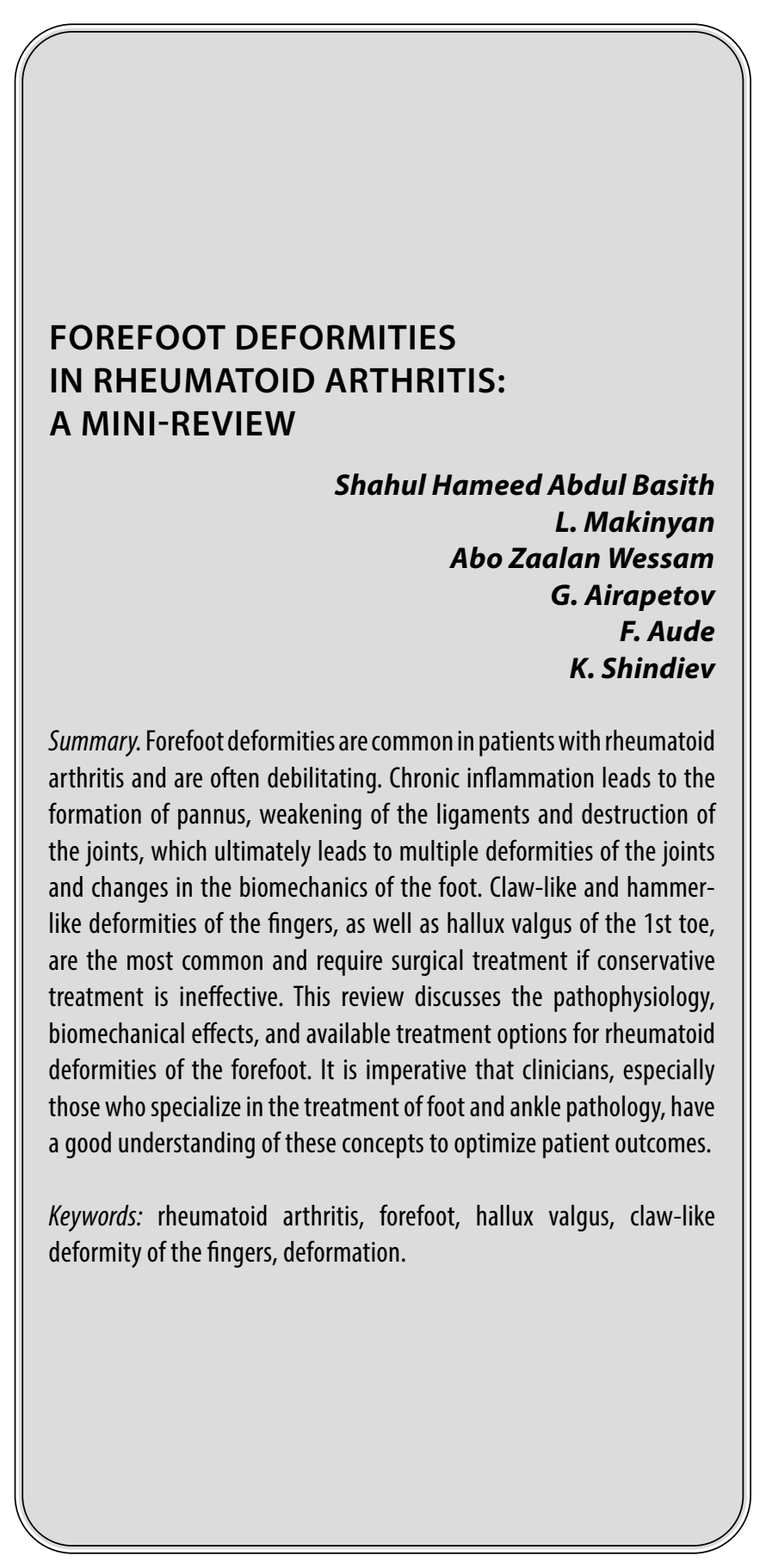

$\mathbf{P}$ евматоидный артрит-хроническое системное воспалительное заболевание, которым страдает примерно 0,8\% населения [1]. В частности, чаще всего поражается передний отдел стопы, и, по оценкам, у $65 \%$ пациентов с ревматоидным артритом в течение
Шахул Хамид Абдул Баситх

К.м.н., Российский университет дружбы народов,

Москва

drabdulbasi@gmail.com

Макинян Левон Гагикович

К.м.н., дочент, Российский университет дружбы народов; Заведующий отделением ортопедии № 2, ГКБ

13, Москва

dr.makinyan@gmail.com

Абу Заалан Вессам

К.м.н., Российский университет дружбы народов,

Москва

wsameeexx@gmail.com

Айрапетов Георгий Александрович

К.м.н., доцент, Ставропольский государственный медицинский университет

airapetovga@yandex.ru

Ауде Фади Салимович

К.м.н., врач травматолог-ортопед, ГКБ № 31,

Москва

Dr.awde.fs@gmail.com

Шиндиев Курбан Ахмедович

К.м.н., Российский университет дружбы народов,

Москва

Kurban-Shindiev@mail.ru

Аннотация. Деформации переднего отдела стопы часто встречаются у пациентов с ревматоидным артритом и часто являются изнурительными. Хроническое воспаление приводит к образованию паннуса, ослаблению связок и разрушению суставов, что в конечном итоге приводит к множественным деформациям суставов и изменению биомеханики стопы. Когтеобразная и молоткообразная деформации пальцев, а также вальгусное отклонение 1-го пальца наиболее распространены и требуют оперативного лечения в случае неэффективности консервативного лечения. В этом обзоре обсуждается патофизиология, биомеханические воздействия и доступные варианты лечения ревматоидных деформаций переднего отдела стопы. Крайне важно, чтобы врачи, особенно те, кто специализируется на лечении патологии стопы и лодыжек, хорошо разбирались в этих концепциях для оптимизации результатов лечения пациентов.

Ключевые слова: ревматоидный артрит, передний отдел стопы, вальгусная деформация, когтеобразная деформация пальцев, деформация.

первых трех лет после начала заболевания наблюдается поражение плюснефалангового сустава (МTP) [2]. Классически у пациентов с ревматоидным артритом наблюдается вальгусная деформация, царапание пальцев ног, опускание медиальной дуги и расширение перед- 
ней части стопы, совокупность симптомов, известных как pied douloureux des rhumatisants [3]. Передний отдел стопы играет неотъемлемую роль в поддержании веса и походке, и поэтому понимание потенциальных последствий деформаций, вторичных по отношению к ревматоидному артриту, а также вариантов лечения крайне важно для оптимального управления. Доступны различные варианты лечения, включая консервативные и хирургические методы. Когда консервативное лечение не помогает, необходимо рассмотреть оперативное лечение, которое может включать резекцию головки плюсневой кости, артропластику с резекцией МТР, укорочение плюсневой кости или фаланги или артродез сустава PIP при деформации когтистого пальца стопы $[1,2]$. Первый артродез сустава МТР или протезная имплантация могут быть рассмотрены для лечения вальгусной деформации [2]. Этот обзор направлен на описание патофизиологии наиболее распространенных деформаций переднего отдела стопы у пациентов с ревматоидным артритом, а также доступных вариантов лечения.

\section{Патофизиология}

При ревматоидном артрите хроническое аутоиммунное воспаление приводит к разрушению и деформациям суставов [1,2]. Аутоиммунный ответ нацелен на синовиальную мембрану, что приводит к воспалению синовиальной оболочки и образованию паннуса. Со временем паннус разрушает нижележащие суставные хрящи и кости [1]. По мере прогрессирования заболевания также поражаются капсулы суставов, связки и связочные вставки, и целостность суставов нарушается. В частности, в стопе распространенные вторичные деформации включают подвывих тарана и смещение задней части стопы [1], вальгусную деформацию [1,2], варусную деформацию пятого сустава МTP $[2,3]$ и вывих сустава МTP [2].

Когтистые пальцы стопы и вальгусная деформация являются двумя наиболее распространенными деформациями суставов переднего отдела стопы при ревматоидном артрите [4]. Слабость суставов приводит к повторяющемуся вывиху дорсального сустава МТР при ходьбе [1]. При хроническом дорсальном вывихе проксимальных фаланг возникает дисбаланс сил, оказываемых внутренними и внешними мышцами [1-3], наряду с контрактурами разгибания [3], и постепенно наступает постоянное сгибание в суставах МТР. Подошвенное сгибание дистальных фаланг происходит одновременно, также вторично по отношению к дисбалансу между силами внутренних и внешних мышц стопы [1,2]. Это приводит к царапанию, что уменьшает поддержку, которую плюсневые кости обеспечивают первому лучу. Отсутствие боковой поддержки приводит к постепен- ному медиальному отклонению первой плюсневой кости и, как следствие, вальгусной деформации [1].

По мере изменения анатомической структуры стопа подвергается биомеханическим изменениям. При гиперэкстензии суставов МТР подошвенная пластина растягивается, а головки плюсневых костей выступают. При переносе веса в родной стопе подошвенная жировая подкладка играет важную роль в минимизации нагрузок, передаваемых головкам плюсневых костей, а также в снижении давления на нижнюю подкожную клетчатку и подошвенную кожу. Однако, когда жировая подушечка смещается, напряжение, передаваемое через головки плюсневых костей, увеличивается, что приводит к метатарзалгии и затруднениям при ходьбе. Кроме того, в отсутствие жировой подушки в качестве промежуточной подушки головки плюсневых костей оказывают повышенное давление на нижние подкожные ткани, что может привести к образованию мозолей и болезненных мешочков $[1,2]$. Перераспределение сил в опоре на вес также происходит при развитии вальгусной деформации. По мере увеличения межметарзального угла между первым и вторым лучом нормальная несущая способность первого луча теряется, и вторая плюсневая кость подвергается повышенной нагрузке. Это может привести к синовиту и возможному перелому, подвывиху, деформации или вывиху второй плюсневой кости [2].

Неоперативное лечение может быть сначала начато для облегчения симптомов и предотвращения развития или прогрессирования деформаций стопы. Доступны различные фармакологические средства, в том числе модифицирующие заболевание противоревматические препараты (DMARDs) [1], которые замедляют клиническое прогрессирование ревматоидного артрита и связанного с ним повреждения суставов $[1,4]$. Внутрисуставные инъекции кортикостероидов также являются жизнеспособным неоперативным вариантом, и в некоторых исследованиях было показано, что они обеспечивают симптоматическое облегчение боли и улучшают походку. Однако необходимо также понимать риски инъекций, поскольку они могут усугубить нестабильность в переднем отделестопы. Физиотерапия, стельки, вставки для обуви и обувь с разгрузкой переднего отдела стопы - это потенциальные вмешательства, которые могут быть полезными. Однако существуют противоречивые доказательства того, являются ли они эффективными [1].

Когда неоперативное лечение оказывается безуспешным, следует рассмотреть возможность хирургического вмешательства. Целью оперативного лечения является облегчение боли и исправление деформации при восстановлении функции [2]. Другая цель состоит в том, чтобы восстановить нормальное распределение давления, переместив подошвенную пластину 
и жировую подушку под плюсневыми костями. Золотым стандартом оперативного лечения деформаций с вовлечением малых плюсневых костей является резекция головок плюсневых костей $[1,2]$. Как правило, для предотвращения метатарзалгии резецируются все четыре головки меньшей плюсневой кости, а не только те, которые являются симптоматическими [2]. Хирургическое вмешательство часто показано для всех пяти плюсневых костей из-за высокой частоты вальгусной деформации, при которой, как было показано, эффективно выполняется реконструкция передней части стопы с первым сращением МТР, резекцией головки меньшей плюсневой кости и сращением сустава PIP [5].

Хотя резекция головки плюсневой кости является наиболее распространенным вариантом лечения и золотым стандартом для деформаций малых лучей $[1,2]$, головки плюсневой кости являются важными структурами для поддержания веса. Таким образом, были разработаны методы сохранения головок во время репозиции мягких тканей, включая артропластику с резекцией МТР, освобождение сухожилий, укорочение фаланг и плюсневых костей и укорочение артродеза суставов PIP. Процедура резекции, которая включает иссечение проксимальной половины проксимальной фаланги, а также тенотомии разгибателей, сохраняет головки плюсневых костей, восстанавливая естественное положение подошвенной жировой подушечки. Серия случаев, проведенных Басом и соавт., продемонстрировала улучшение показателей боли и функциональности у 12 пациентов, которым впервые был проведен артродез ТМТ в сочетании с процедурой Стейна [4]. Хотя необходимы более масштабные проспективные исследования, эти результаты могут указывать на потенциально безопасный и эффективный подход к сохранению головок плюсневых костей.

Лечение вальгусной деформации может быть выполнено путем резекционной эндопротезирования, первого сращения МТП или имплантации протеза в первый сустав МТП. Было предложено, чтобы сращивание суставов МТР было выгодным в том смысле, что оно защищает меньшие суставы МТР от чрезмерного сгибания и уменьшает нагрузку на меньшие плюсневые кости. Однако это технически сложная процедура, при которой доля неучастия составляет до 30\%. Также использовались силиконовые протезы, поскольку они со- храняют подвижность суставов и продемонстрировали значительное снижение уровня боли. Тем не менее, общие показатели удовлетворенности были противоречивыми, и существует связанный с этим риск синовита твердых частиц [2]. Поскольку первый луч играет неотъемлемую роль в поддержании веса, важно выбрать соответствующую процедуру для оптимизации послеоперационной биомеханики стопы.

Осложнения, которые могут возникнуть при оперативном лечении ревматических деформаций переднего отдела стопы, всегда следует учитывать, чтобы можно было сравнить риски и преимущества хирургического вмешательства. Васкулит ослабляет мягкие ткани, а хроническое применение иммунодепрессантов предрасполагает этих пациентов к нарушению заживления ран и инфекции. Яно и др. [6] сообщили о замедленном заживлении ран у 20,8\% из когорты из 192 пациентов с ревматоидным артритом и обнаружили значительные ассоциации со временем операции, количеством прооперированных пальцев и количеством хирургических ран. К сожалению, пациенты с ревматоидным артритом часто имеют деформации нескольких (если не всех) пальцев ног, что требует множественных разрезов и требует более длительного времени операции [6]. Васкулит также может привести к повреждению сосудов и последующей гангрене. Остеопения часто встречается у пациентов с ревматоидным артритом, что может способствовать нарушению обмена веществ. Кроме того, хотя хирургическое вмешательство может исправить деформации суставов, оно не может лечить основное заболевание, и поэтому деформации, скорее всего, повторятся [1].

\section{BывоА}

Деформации суставов переднего отдела стопы, вызванные ревматоидным артритом, являются изнурительными для пациентов и требуют тщательного внимания и ухода со стороны врача. Из-за высокой частоты этих деформаций в этой популяции хирурги стопы и голеностопного сустава должны быть осведомлены о вариантах лечения, рисках и преимуществах. Медицинское сообщество должно продолжать искать варианты лечения и процедуры для оптимизации результатов лечения пациентов с деформациями переднего отдела стопы, вторичными по отношению к ревматоидному артриту.

\section{ЛИТЕРАТУРА}

1. Дженг С., Кэмпбелл Дж. (2008) 0бзор современных концепций: Ревматоидная деформация переднего отдела стопы. Голеностопный сустав стопы Int 29(9): 959-968.

2. Луверенс JWK, Шриер JCM (2013) Ревматоидная деформация переднего отдела стопы: патофизиология, оценка и варианты оперативного лечения. В ортопе 37(9): 1719-1729. 
3. Дэйв М.Х., Мейсон Л.В., Харихаран К. (2015) Деформация переднего отдела стопы при ревматоидном артрите: Сравнение групп населения в обуви и без обуви. Спецификация лодыжки стопы 8(5): 378-383.

4. Басс Э. Дж., Шарифф Р., Сириконда С.П. (2014) Ревматоидная реконструкция переднего отдела стопы: результат сращения 1-го плюснефалангового сустава и процедуры Стейнсби в нижних пальцах ног. Фут 24(2): 56-61.

5. Уитт К. Дж., Ринкер С.А., Хайер К.Ф. (2016) Устойчивость реконструкции переднего отдела стопы при ревматоидном артрите стопы. J Операция на лодыжке стопы 55(3): 583-585.

6. Яно К, Икари К, Такацуки У, Танигути А, Яманака Х. и др. (2016) Более длительное время операции является риском замедленного заживления ран после операции на переднем отделе стопы у пациентов с ревматоидным артритом. Мод Ревматол 26(2): 211-215.

○ Шахул Хамид Абдул Баситх ( drabdulbasi@gmail.com ), Макинян Левон Гагикович (dr.makinyan@gmail.com ),
Абу Заалан Вессам ( wsameeexх@gmail.com ), Айрапетов Георгий Александрович ( airapetovga@yandex.ru ),
Ауде Фади Салимович ( Dr.awde.fs@gmail.com ),Шиндиев Курбан Ахмедович ( Kurban-Shindiev@mail.ru ). Журнал «Современная наука: актуальные проблемы теории и практики»

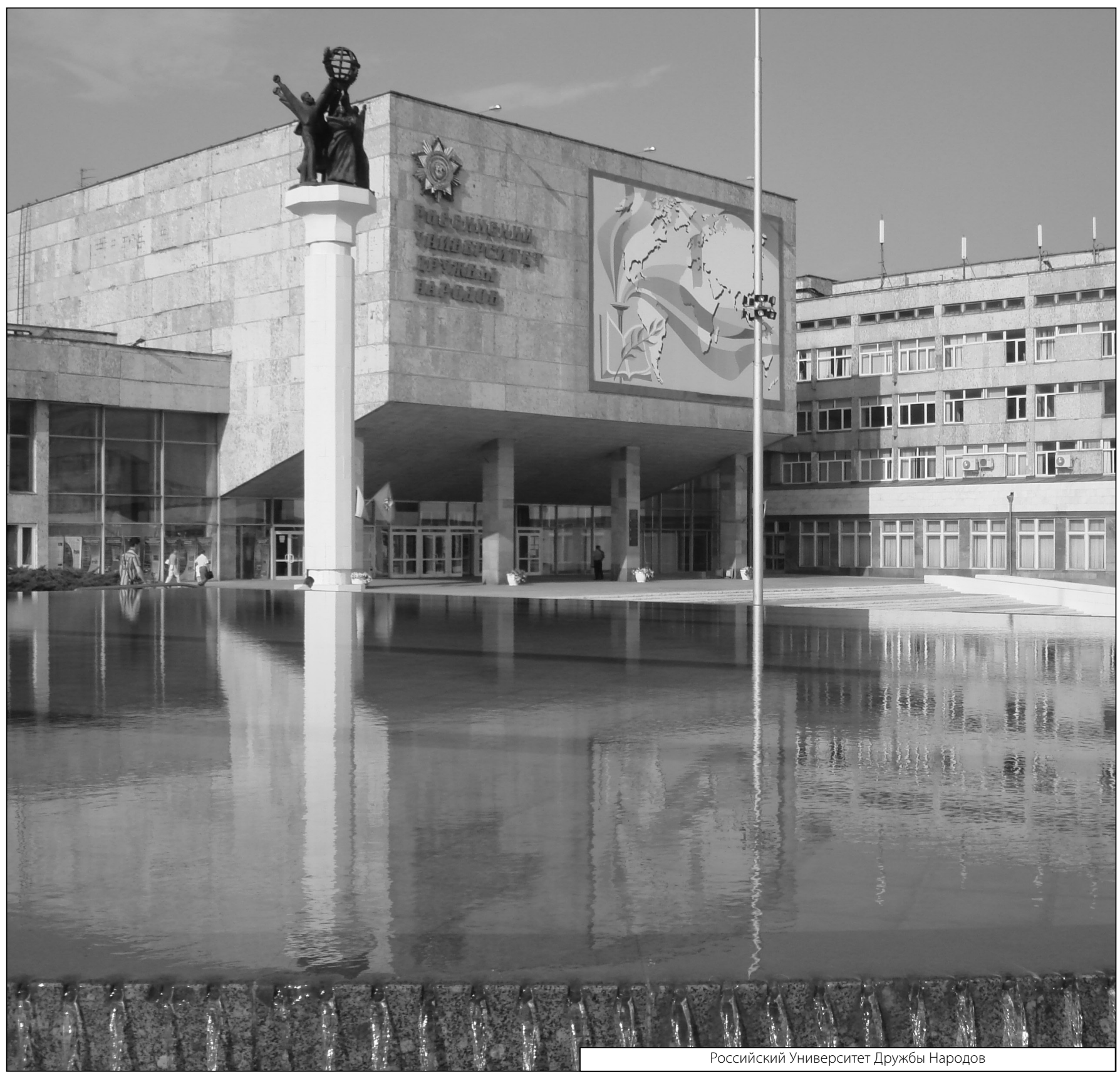

